\title{
Media technologies and museology: development prospects in the modern communication space
}

\author{
Diana Volkova ${ }^{1}$, Elena Sklyarova ${ }^{2 *}$, Inna Topchiy ${ }^{1}$, and Evgeniya Kosyanenko ${ }^{1}$ \\ ${ }^{1}$ Don State Technical University, Gagarin sq., 1, Rostov-on-Don, 344003, Russia \\ ${ }^{2}$ Rostov State Medical University, Nakhichevansky, 29, Rostov-on-Don, 344022, Russia
}

\begin{abstract}
The article discusses the development prospects of media technologies in the communication space in the context of the evolution of the education system, public health and museology in Russia and abroad. Basing on an interdisciplinary approach, historical-genetic and comparative research methods, the features of the use of modern media technologies and museology in the transition to a system of distance education and telemedicine are analyzed. While the XVI century had become a period of transition from manuscripts to printed editions, XIX century became the era of the industrial revolution, the beginning of the XXI century will go down as the "electronic-distance revolution", implemented by the graduates of the universities of the USSR, China, Denmark and the USA. It is concluded that in the context of the pandemic, a radical transformation of the education system, museology and health care has taken place. With the transition to distance education and telemedicine, the importance and demand for those universities, hospitals and museums has increased, which in a timely manner switched to the active use of modern media technologies. The importance of medical museology as a new branch of humanitarian knowledge, which determines the prospects for the progressive development of healthcare in the modern communication space, increases as well.
\end{abstract}

\section{Introduction}

EarlyXXIcenturywillgodownintheworldhistoryasatransitionalperiodintheeducationandhealt hcaresystemassociatedwiththewidespreaduseofmediatechnologiesinthemoderncommunicati onspace.Massive transition to the use of the first printed books and publications began in the XVI century, while about five hundred years later there is a massive dismissal of printed publications and document circulation from public life. These processes which are associated with the transformation of education, museology, public consciousness and health care have not been comprehensively studied in the context of the use of media technologies. The relevance these problems' study is determined by their scientific and practical significance, global importance, by the need to use an interdisciplinary approach.It

*Corresponding author: afina18@mail.ru 
should be noted that these processes did not come as an innovation during the 2020 pandemic.Even in previous years, attempts were made to analyze the problem appropriately over the past forty years on the pages of "Distance Education" in the context of "flexible learning and flexibility" [1]. Problems such as availability of distance education at any time, its flexibility and quality, cultural and national differences, were raised.

Despite the advantages of teleworking, a number of problems and disadvantages were noted. The "digital transformation" in the education system has been critically examined in the context of the analysis of the activities of seventy-five Chinese universities. The modernization of the training system in China is interconnected with "efficiency innovations in teaching and learning" in all countries of the world [2]. At the same time, the need is noted for a complete computer modernization of universities' equipment, for new ethical standards for their functioning and the conduct of examinations (national and international) to be worked out. Assessment of videoconferencing system in the context of education quality [3] has become a subject of scrutiny and criticism.It should be noted that differences and quality of video conferencing in Microsoft Teams, Skype, Zoomhas become the subject of comparison. To a lesser extent, researchers focus on functioning of medical universities which use Google Meet for distance learning and on possibilities for medical museology.

A scientific review of modern scientific publications confirms the increased scientific and practical interest in all these problems in the world and particularly in Russia.However, until now, these issues have not been covered in the context of peculiarities of use, their interconnection and development prospects in the modern communication space of media technologies, museology. The relevance of their research is closely related to the need for comparative scientific research on the evolution of the university medical education system, as well as the prospects for its development in the context of public health and use of museology. These problems have not been studied comprehensively in foreign and domestic historiography in a comparative historical aspect, revealing the socio-medical and political features of use of media technologies in Russia and abroad.

\section{Materials and methods}

The analysis of features of use and prospects for the development of media technologies in the modern communication space, studied in the context of the evolution of university education system, public health and museology, was carried out on the basis of an interdisciplinary approach, as well as utilizing historical-genetic and historical-comparative research methods. To compare the specifics of the use of media technologies in the modern communication space in Russia and abroad, "periodicals of Russian and foreign university and medical centers, representatives of museology and public health were used.An analysis of modern electronic publications and sites enabled comparisonsof evolutionary features and dynamics of a new format of training sessions, museology, video conferencing (Google Meet, Microsoft Teams, Skype, WhatsApp, Zoom), electronic exhibitions and publications in the context of expanding the potential audience and international use.Historical-genetic and historical-comparative research methods made it possible to determine the evolution and range of the use of media technologies in Russia and abroad, the features and new possibilities of the distance education system, health care and museology. These scientific research methods made it possible to identify and compare the initial stage of these processes, as well as dynamics and content of the corresponding innovations in Russia and abroad.

On the basis of an interdisciplinary approach, new realities and features of the use of media technologies in the transition to distance education, telemedicine and museology, which have a negative or promising significance for the development of countries of the 
world, international cooperation and human beings, have been identified. The use of an interdisciplinary approach made it possible to compare the actual problems of the "electronic-distance revolution" in the USSR, Russia and in other countries of the world.All these scientific research methods made it possible to identify positive and negative features, consequences and prospects for the development of media technologies and museology in the modern communication space in Russia and abroad.

\section{Results}

At the beginning of the 21st century, amid a pandemic, all countries of the world underwent a radical transformation of the education and public health systems. The pandemic has adjusted the system of work of schools and universities around the world, medical centers, various museums and cultural objects.In transition to distance education and telemedicine in Russia and abroad, the increase in importance and demand was seen for those universities, medical centers and museums of the world which switched to active use of modern media technologiesin a timely manner.In recent years, many leading universities and large medical centers in Russia and in the world have created their own virtual pages and museums. To provide for modern educational content based on the widespread use of web services and relevant tools, universities in Russia and the world began to develop new educational programs using modern media technologies.Beginning with the $21 \mathrm{st}$ century,the corresponding structure of new educational standards in Russian universities is aimed at a gradual transition to the widespread use of modern media technologies (initially starting at $10 \%$ of the total number of hours), providing for more flexible approaches to the educational process and the possibility of further upgrade of equipment and media technologies.Teachers and students who mastered the format of conducting classes as electronic presentations quickly switched to their use in transit to distance education.Medical centers in Russia and other countries where using media technologies is not a problem for medical personnel have a significantly larger number of clients under self-isolationIn modern conditions, using the new capabilities of telemedicine, one can get qualified advice in Russia'sleading medical centers (in Moscow, St. Petersburg, Volgograd, Rostov-on-Don, Stavropol, Ufa, etc.), as well as in various countries of the world (Israel, China, England, France, USA, etc.).

In recent years, a system of preparing electronic textbooks and teaching aids in medical universities in Russia has met the greatest demand [4].Accordingly, those departments that had carried out the publication of their own electronic textbooks in a timely manner were able to perform a complete and quick transfer to distance learning for their students.Electronic scientific journals of Russia, which in recent years have also timely switched to electronic format of publicationshave provided great assistance in transition to the system of distance education in medical universities, having received international and all-Russian recognition [5].At the same time, paper publications, often lacking modern information metadata and electronic identification systems that meet international standards quickly began to lose their scientific and commercial relevance in the international scientific community of the 21 st century.

For comparison, it should be emphasized that in the world history of science, culture, medicine and university education, the process of transition from manuscripts to printed editions beganin the 16th century. "The first Russian book printer - Ivan Fedorov" became the founder of the first printing house in Russia (in Moscow), and then in The Commonwealth [6].Innovations such as the first printed books, special letters, fonts, discs for engravings, a printing press, came to the Russian kingdom from printing houses in Denmark, Venice, and Poland.The rise of typographic publications began through religious literature, book printers opposedby the clergy due to the competition to monks, who had 
beenmanually copyingmanuscripts (often with errors) asan outdated method.Gradually, their work in the XVI century was supplanted by innovations of printing houses, the massive use of printed books. In the year of the 2020 pandemic, against the backdrop of a massive transition of countries around the world to electronicdistance learning, the 500th anniversary of Ivan Fedorovwas celebrated. The beginning of book-printingis captured in various museums and by monuments in Russia and elsewhere the world.

The next important milestone in the history of human development was the XIX century, which marked the era of the industrial revolution in Great Britain and in the world.Consequentiallycame the transformation of an agrarian society into an industrial one. James Watt, aScottish engineer, member of the Royal Society of Edinburgh and of the Royal Society of London invented the steam engine, initiating the Industrial Revolution. His inventions became an integral part of the Science Museum in London which was founded back in 1857.In the halls of the museum, inventions in the field of physics, chemistry, electricity, printing presses are presented. The museum collaborates with the Bradford National Media Museum. The exhibits of artifacts that led to the global transformation of mankind and communications (cable, radio, speech constellation, telephone, camera) became attractions.In the XXI century the museum is part of the Science Museum Group andit actively uses modern media technologies and virtual exhibitions, opening up access to the study of innovations in science, technology and medicine for residents of all countries of the world. The Science Museum of London is a member of the London Museums of Health \& Medicine group. All leading museums in the world including medical oneshave their own virtual pages and exhibitionssince the beginning of the XXI century.

Gradual ousting of man from production through technical innovations and a change in the mentality of nations and the structure of society became a consequence of the industrial revolution. This process was accompanied by urbanization which resulted in the rise of mass epidemics (typhoid, cholera, tuberculosis, whooping cough, etc.) and environmental pollution. Owing to the industrial revolution, the introduction of technical innovations in the mass publication of newspapers and magazines, the formation of mass media technologies began. This process led to the beginning of the publication of most modern newspapers and magazines, including medical ones (Times, The Lancet, The Spectator, The Economist, etc.). There was a formation of a new system of periodicals, of public health care, as well as "new ideas of social development" [7].By the middle of the XIX century, in Great Britain "the formation of public health as a new direction of social policy was already underway" [8]. "British museums have become a sociocultural phenomenon of the era of Queen Victoria and the era of urbanization" [9]. The new ideas of social development were substantiated by the middle of the 19th century in the era of urbanization, "becoming an integral element of Benthamism, Victorianism and social policy of countries of the world" [10].«In the post-war period, the recognition of the social activities of the participants in the Crimean War led to the creation of a memorial complex of the Crimean Guard in London. The monument to the heroes of the Crimean War was erected in front of the Waterloo Palace ...Monuments to Minister of War Lord S. Herbert and F. Nightingale were later erected in memory of the Crimean War in the twentieth century» [11]. Formation of public health care, medical museology, and periodicals becamea consequence of the industrial revolution, urbanization, and Victorianism.

The early XXI century will go down in the world history as an "electronicdistance revolution". It has been noted in the studies that, for the first time, the use of video conferencing began as early as in the 1960 s, but "did not receive sufficient distribution in organizations due to their high cost ... however, due to rapid development of technologies, modernization of special equipment and the development of a computer network, the use of video conferencing already became more popular in the late 1990s. [12].It has been noted 
in the research by scientists from the Universities of Leicester and Cambridge in 2010that in the last two decades, "videoconferencing has become more widely used in the system of higher, and then secondaryeducation" [13]. In the transition to a new distance learning format, media technologies are optimally suited toaccomodate the entire block of subjects of the socio-humanitarian cycle studied at universities in Russia and all over the world.Various companies offer their services in the areas of communication, distance education, museology, medicine and healthcare development in Russia and elsewhere in the world, including Google Meet, Microsoft Teams, Skype, WhatsApp, Zoom, most of which represent US media technologies (Table 1):

Table 1. Internet media technology companies.

\begin{tabular}{|c|c|c|c|c|}
\hline & Company & Country, city & Created in & Founders \\
\hline 1 & Google Meet & $\begin{array}{c}\text { USA, } \\
\text { MountainView, California }\end{array}$ & 2017 & $\begin{array}{l}\text { L. Page, } \\
\text { S. Brin (Stanford University) }\end{array}$ \\
\hline 2 & $\begin{array}{l}\text { MicrosoftTea } \\
\mathrm{ms}\end{array}$ & $\begin{array}{l}\text { USA, Redmond, } \\
\text { Washingtonstate }\end{array}$ & 2016 & \\
\hline 3 & Skype & $\begin{array}{l}\text { Luxembourg, Estonia } \\
\text { (Tallinn, Tartu). }\end{array}$ & 2003 & $\begin{array}{l}\text { N. Zennström, } \\
\text { J. Friis }\end{array}$ \\
\hline 4 & WhatsApp & $\begin{array}{c}\text { USA, } \\
\text { MountainView, California }\end{array}$ & 2009 & $\begin{array}{l}\text { J. Coom (University of San Jose), } \\
\text { B. Acton (Stanford University) }\end{array}$ \\
\hline 5 & Zoom & $\begin{array}{c}\text { USA, } \\
\text { SanJose, } \\
\text { California } \\
\end{array}$ & 2011 & $\begin{array}{l}\text { Eric S. Yuan } \\
\text { (Shandong University, China; } \\
\text { Stanford University, USA) }\end{array}$ \\
\hline
\end{tabular}

Google is a US corporation, originally registered as a private company in 1996. It was founded by Larry Page and Sergey Brin, who then were studying at Stanford University in California.This was originally their research project. As of 2020, Paige is the tenth richest person in the world, and is included in the Forbes ranking of the most influential people in the world. Sergey Brin was born in the USSR in Moscow. His parents are graduates of the Faculty of Mechanics and Mathematics of Moscow State University. His father was a researcher at the Economic Research Institute under the USSR State Planning Committee, then became a teacher and honorary professor at the University of Maryland. Sergey Brin immigrated to the USA from the USSR at the age of six [14]. He earned a bachelor's degree from the University of Maryland, studying mathematics and computer science, and then a doctorate in computer science from Stanford University, where he met L. Page. Theinnovators together created a new search engine. As of 2020, S. Brin ranked as the 7th richest person in the world, in 2011 he donated $\$ 500,000$ to the Wikipedia project. S. Brin and L. Page remain at Alphabet as members of the board of directors, jointly studying the problem of gerontology - human aging.

Considered one of the "big four" technology companies along with Amazon, Apple, Microsoft, Google develops a number of Internet products.Its mission was to "organize world's information, making it accessible and useful for everyone." The unofficial slogan of the company, invented by Google engineer P. Buckheit, is "Don't be evil". In 2003, the company moved to its headquarters in Mountain View, California. Google has Gmail, Google Chromeweb browser, Hangouts. In 2011, the number of monthly visitors to Google sites exceeded one billion for the first time. Computer History Museum, a museum for the history of computing is also located in Mountain View, California [15].Hangouts has evolved into a new premium product called Google Meet. Its first release was published in February 2017, and in March the program was officially presented.Three years later, in March 2020, in relation with the COVID-19 pandemic, it was announced that Google would provide free access to this software. This rapid advancement in media technology has resulted in a thirtyfold increase in the number of users in April 2020 compared to January 2020, reaching 100 million users per day.At that time, a similar service Zoom had 200 million users per day. The advantage of Google Meet is its extended features including 
video meetings with up to 250 simultaneous users, as well as video recording and live streaming of video meetings for domain users. This is an optimal and wider audience for lectures, academic competitions, conferences. When working with Google Meet, universities use available functions: conducting lectures, group video meetings, virtual tours. You can start a video meeting by inviting participants using Google Meet, Gmail, Calendar, via a link. A free version is available for regular users, allowing video meetings up to 100 users, lasting up to 60 minutes. Initially, this communication system was created for business, but in the context of the pandemic, it became available or free for all interested users.

Microsoft Teams is an enterprise platform developed by Microsoft. The service was introduced in 2016. Microsoft Teams is part of Office 365, distributed through a corporate subscription. Microsoft announced Teams in New York, planning to launch the service in 2017. In March 2019, meetings productivityupdates were released. American entrepreneur and philanthropist William Gates together with Paul Allen became the founders of Microsoft. The company is headquartered in Redmond, Washington, USA. Microsoft has been operating in Russia since 1992 (via Microsoft Rus LLCsince 2004). Teams does not allow non-subscription members to join the platform.

WhatsApp is a popular free instant messaging system for mobile platforms with voice and video support. The company was founded by Jan Kum and Brian Acton in 2009. J. Kum was born in the USSR, in Kiev. In 1992 he emigrated to the United States in Mountain View. Educated at the University of San Jose, Kum worked in the information security department of Ernst \& Young. In 2014, Whatsappwas sold to Facebook, making J. Kum a billionaire (according to Forbes). B. Acton was born in the USA and graduated from Stanford University in 1994 with a degree in computer science. Like many other companies, WhatsApp is based in the United States in Mountain View. Since 2014, WhatsApp has been owned by Facebook. By 2015, WhatsApp had become the most popular messaging application in the world. Since 2016, the application has become free.

Zoom is considered a competitor to Google Meet and Microsoft Teams. It was founded in 2011 and is headquartered in the United States in San Jose, California, with branches around the world. Eric S. Yuan is a Chinese-American billionaire, CEO and founder of Zoom Video Communications. He received his Bachelor's degree in Applied Mathematics in China from Shandong University of Science and Technology, and then studied Business Administration at Stanford University.In 2019, Zoom went public and Yuan became a billionaire. Innovative communication platforms provide video conferencing, webinars, chats. Zoom's video conferencing software lets you connect up to 100 devices simultaneously for free. Users have the opportunity to upgrade the service using a billing plan with a maximum number of up to 500 connections simultaneously, without time limits.Initially, Zoom had the ability to host conferences for up to 15 people. During the COVID-19 pandemic, Zoom has exploded in popularity for social communication and distance learning.

Skype is a free software for video communication over the Internet between computers, including paid services to call mobile phones. The company was founded in 2003 in Luxembourg. The program was created by Swedish entrepreneurs NiklasZennström and Danish Janus Friis. Philanthropist N. Zennström headed Tele2 in Denmark, dealt with climate and environmental issues. In 2011 Skype was sold to Microsoft. Most of the developers are also located in Estonia (Tallinn, Tartu). The program allows you to make conference calls, video calls with to up to 50 participants, including the initiator.

Advanced training, professional growth of employees, providing training in new computer technologies, has been carried out in all universities in Russia in recent years. Interactive methods of work and teaching in universities have proven their effectiveness in holding international conferences, all-Russian academic Olympiads, defending doctoral and 
candidate dissertations. The process of submitting and processing the relevant documents at universities and medical centers has been greatly simplified.

\section{Discussion}

With transition to mass use of media technologies in the modern communication space, the prospects for their development have become an object of modern scientific discussions. «The effectiveness or inefficiency of the use of information and communication technologies in the marketing activities of the University, despite the versatile coverage of the topic for all participating subjects, remains quite complex, ambiguous and not fully studied» [16]. «With the development of the theory of multimodality is connected the fact that the changes begin to occur not only in the media, in magazines, but also in the official documentation of various corporations, universities, government departments, i.e. in the sociopolitical sphere, as color illustrations and a complex layout appear in this documentation» [17].

Media technologies as a method of communication and information processing have become an integral part of distance learning and healthcare. Commercial limitations on free conferences, their cost and duration will pose a problem for their use at universities, medical centers and museums around the world. Limitedduration of video calls can be a problem for low-income institutions. Subjects of multimedia - developers, publishers of multimedia products, distributors, providers and users of Internet resources and multimedia products will depend on the expansion of the corresponding services in the areas of education, museology and health. In the context of the pandemic, 2020 became a period of massive transition to the use of media technologies in Russia and in the world, which will further lead to increased competition and the development of new media technologies. The question of training level of moderators, representatives of relevant directionsin science, health care, museology and education is reasonably raised.

\section{Conclusions}

Thus, the study of the evolution, dynamics and features of the use of media technologies in the communication space in the context of the evolution of university education, public health and museology in Russia and abroad shows that the transition to the use of various media technologies began in the XX century. The massive transition to a distance education system and telemedicine during the pandemic has consolidated all the previous innovations of countries of the world.In the XVI century,a transition from manuscripts to printed editions began. XIX century marked the era of the industrial revolution that began in Great Britain, which resulted in the transformation of an agrarian society into an industrial one, the transition to public health, the formation of medical museology, as well as to a global transformation of the mentality of mankind. Museums actively use modern media technologies and virtual exhibitions, which open access to the study of innovations in science, technology and medicine for residents of all countries around the world..The industrial revolution resulted in urbanization, the emergence of a public health and social policy system, further globalization, and a change in the mentality of nations. The "electronic distance revolution" is a consequence of urbanization and industrial revolution, the development of public health and museology, as well as epidemics and pandemics. The use of video conferencing, initiated in the 1960s, led to rapid development of media technology in the United States, reducing the cost and modernizing the computer network in universities and medical centers around the world. The "electronic distance revolution" has led to a radical transformation of the education system, medicine, museology and public 
health. Its implementation was contributed to by graduates of universities of the USSR, China, Denmark, USA. In Russia, the demand for the universities, hospitals and museums of the world which in a timely manner switched to the active use of modern media technologies was seen increasing. In the XXI century, the choice of one medical center, object of culture and education over another began to largely depend on the prospects for the use and development of media technologies in the modern communication space of the countries of the world.

\section{References}

1. G.Veletsianos, S. Houlden, Distance Education, 40(4), 454-468 (2019) doi.org/10.1080/01587919.2019.1681893

2. J. Xiao, Distance Education, 40(4), 515-553 (2019) doi.org/10.1080/01587919.2019.1680272

3. D. Candarli, G.Yuksel, Procedia-Social and Behavioral Sciences, 47, 357-361 (2012) doi.org/10.1016/j.sbspro.2012.06.663

4. E. Sklyarova, M. Gutieva, G. Gafiyatullina, O. Kamalova, English Medium: History: in Sheme and Tables (2018)

5. N. Drobotya, E. Chaplygina, O. Kamalova, E. Sklyarova, Science almanah of Black Sea region countries, 1 (9), 41 - 47 (2017) doi.org/10.23947/2414-1143-2017-9-41-47

6. E.Sklyarova, M. Gutieva, G. Gafiyatullina, O. Kamalova, English Medium: History, 21, (2018)

7. V. Aprychenko, E. Sklyarova, Dialog So Vremenem-dialoguewith Time, 70, 251 264, (2020), WOSUID: WOS:000519565500017

8. E. Sklyarova, Ylia Sidorenko, Andrey Safronenko, Elena Butova, Bylye Gody, 54(4), 1625, (2019) doi.org/10.13187/bg.2019.4.1623

9. D. Volkova, E. Sklyarova, I. Topchiy, Humanities and socio-economic sciences, 3 (106), 92 (2019) 10.23683/1997-2377-2019-106-3-88-93

10. E. Sklyarova, M. Gutieva, O. Kamalova, L. Zaseeva, Bylye Gody, 3(53), 1111 (2019) 10.13187/bg.2019.3.1106

11. E. Sklyarova, O. Kamalova, Science almanac of Black Sea region countries, 24(4),85, (2020) 10.23947/2414-1143-2020-24-4-82-88

12. A.-P. Correia, C. Liu, F. Xu, Distance Education, 41(4), 430, (2020) doi.org/10.1080/01587919.2020.1821607

13. T. Lawson, C. Comber, J. Gage, et al., Technology, Pedagogy and Education, 19(3), 295-314 (2010) doi.org/10.1080/1475939X.2010.513761

14. I. Iosebashvili, The Wall Street Journal, June 21, (2010)

15. G. Bell, Microsoft Technical Report MSR-TR-2011-44, April 30, (2011)

16. A. Babaitsev, I. Topchiy, S. Voskoboynikov, Proceedings of the International Scientific Conference "Digitalization of Education: History, Trends and Prospects", (2020) doi.org/10.2991/assehr.k.200509.099

17. N. Gafiatulina, N. Shishova, D. Volkova, I. Topchiy, E3S Web Conferences, 175, 15031 (2020) INTERAGROMASH 2020

https://doi.org/10.1051/e3sconf/202017515031 